\title{
Packaging and Storage of Olive Oil
}

\author{
Amalia Piscopo and Marco Poiana
}

Additional information is available at the end of the chapter

http://dx.doi.org/10.5772/51827

\section{Introduction}

Storage is a very important step of any food, including olive oil. In fact, olive oil shelf life can be influenced by different factors, from olive quality to processing technologies, however, the selection of proper storage conditions, including packaging, can be of great importance. The Mediterranean diet is recommended as food model for the prevention of various chronic-degenerative pathologies (cardiac diseases, cancer etc.) and olive oil is surely the cornerstone of this type of nutrition with fruits, vegetables, legumes and fish. Its peculiar nutritional characteristics depend on the presence of antioxidant components and monounsaturated fatty acids that are predominant on unsaturated ones, with positive results in the increase of HDL (High-Density Lipoproteins) and reduction of LDL (LowDensity Lipoproteins) oxidation.

The consumer expresses its judgment on olive oil quality considering only some sensory characteristics, such as the more or less pungent taste, fruity and mild flavour and within this context a wide range of preferences can be found, because the sensory quality may match specific dishes, cultural aspects or simple dietary habits. Incorrect storage practices influence the sensory quality of the oil, as rancidity and off-flavours may develop. The lipid oxidation, in fact, is one of the factors of olive oil quality deterioration. The rate of oxidation depends on the availability of oxygen, the presence of light and the temperature. In absence of light, the autooxidation follows a free radical mechanism with the formation of hydroperoxides. These labile compounds further decompose to produce a complex mixture of volatile compounds such as aldehydes, ketones, hydrocarbons, alcohols, and esters responsible for the already mentioned deterioration of olive oil flavour known as "oxidative rancidity". Many phenolic compounds of the olive oil contribute to its resistance to oxidative rancidity. After light exposition, photooxidation occurs through the action of natural photosensitizers (i.e. chlorophyll), which react with triplet oxygen to form the excited state singlet oxygen. It then gives a free radical from unsaturated fatty acids, leading to the production of hydroperoxides and eventually to carbonyl compounds, which result in the development of undesirable off flavours in oils. 
Packaging can directly influence olive oil quality by protecting the product from both oxygen and light. The shelf life of the oils exposed to intense artificial light and diffused daylight is shorter than that of oils kept in the dark. Moreover, the storage temperature, the use of nitrogen atmosphere and the reduction of the oxygen in the headspace volume can appreciably control quality changes during storage time.

Materials which have been used for olive oil packaging include glass, metals (tin-coated steel) and more recently plastics and plastics coated paperboard. Among plastics, polyethylene terephthalate (PET) has captured a large portion of the olive oil retail market due to its many advantages including clarity, chemical inertness, low oxygen permeability, and excellent mechanical properties. Incorporation of pigments and/or UV blocking agents or oxygen scavengers may improve plastics properties with regard to quality retention of olive oil. Besides PET, polyethylene (PE) in the form of LDPE-coated paperboard/aluminium foil laminates, i.e. brick-type cartons and bag-in-box pouches and polypropylene (PP) are being used today for the packaging of vegetable oils including olive oil. In this chapter, factors affecting olive oil quality during storage will be discussed and various packaging solutions will be approached.

The aim is to give evidence the best practices to adequately manage this important unit operation, in order to improve/maintain the quality characteristics of the olive oil.

\section{Nutritional value of olive oil}

Mediterranean food tradition is sustained by three basic essentials: wheat, olives and grapes. Nevertheless, olive oil is the central element inherent to this diet, and its importance is due to the increasing consumption around the world, because of its nutritional and sensory properties. European Union (EU) is the leading producer of olive oil and within the EU, the Mediterranean members are the biggest producers, in fact Mediterranean area accounts for $95 \%$ of world production and $85 \%$ of world consumption of olive oil (IOOC, 2007).

Several clinical data have shown that consumption of olive oil can provide heart health benefits, such as favourable effects on cholesterol regulation and LDL cholesterol oxidation, and that it exerts anti-inflammatory, antithrombotic and antihypertensive effects (Lairon, 2007; Perez-Jimenez et al., 2007).

Virgin olive oil is a genuine fruit juice obtained from olive drupes (Olea europaea L.), using exclusively mechanical procedures, without further treatments or chemical additions. The saponifiable fraction is more representative (about 98\%) than the unsaponifiable one and it comprises principally triacylglycerols, esters formed by glycerol and fatty acids, mainly unsaturated acids whose the major is oleic acid (about 65-80\%). The olive oil contains also a relatively reduced level of polyunsaturated essential fatty acids (PUFA), linoleic and linolenic acids (C18:2 $\omega-6, \mathrm{C} 18: 3 \omega-3)$. Such composition gives good resistance to chemical and biological oxidation, in contrast with other edible oils in which polyunsaturated fatty acids prevail on monounsaturated ones (Rastrelli et al., 2002). Thus, the importance of virgin olive oil is related to its high levels of monounsaturated fatty acids but also to the presence 
of minor components including aliphatic and triterpenic alcohols, sterols, hydrocarbons, volatile compounds, and several antioxidants. In fact, the unsaponifiable fraction which covers a small percentage $(0,5-3 \%)$ plays a significant role on human health.

Among the antioxidant compounds, squalene, a triterpenoid hydrocarbon and precursor of sterol biosynthesis, occurs in olive oil with a high concentration (up to 1\%). Other active constituents in the olive oil are represented by tocopherols $\alpha-, \beta-, \gamma-, \delta-$ : the concentration of $\alpha$-tocopherol (Vitamin E), traditionally considered as the major antioxidant, covers almost $88 \%$ of the total tocopherols. The tocopherol content of olive oil depends not only on the presence of these compounds in olive fruit but also on several other factors, involved in the transportation, storage and olive fruit processing. Normally in animal fluids and tissues, vitamin E works in synergy with coenzyme $\mathrm{Q}(\mathrm{CoQ})$ to protect cells and tissues against lipoperoxidation, and some authors detected $\mathrm{CoQ}_{9}$ and $\mathrm{CoQ}_{10}$ in olive oil (Pregnolato et al., 1994; Psomiadou \& Tsimidou, 1998). According to Viola (1997), the ratio of vitamin-E to polyunsaturated fatty acids in olive oils is better than in other edible oils.

Phenolic compounds make an important contribute to the nutritional properties, sensory characteristics and the shelf life of olive oil, because they improve the resistance to the autoxidation. Olive fruit contains simple and complex phenolic compounds: those derived from the hydrolysis of oleuropein contribute to the intensity of the bitterness of virgin olive oil, and especially hydroxytyrosol, tyrosol, caffeic, coumaric and p-hydroxybenzoic acids influence the sensory characteristics of olive oil (Kiritsakis, 1998). The concentration and composition of phenolic compounds in virgin olive oil is strongly affected by many agronomical and technological factors, such as olive cultivar (Tura et al., 2007), place of cultivation (Vinha et al., 2005), climate, degree of maturation (Kalua et al., 2005; Sicari et al., 2009; Giuffrè et al., 2010), crop season (Gómez-Alonso et al., 2002), irrigation (Tovar et al., 2001) and production process (Cinquanta et al., 1997; Ranalli et al., 2001).

Regarding other compounds in the olive oil, its colour is mainly related to the presence of chlorophyll and pheophytin a (Psomiadou \& Tsimidou, 2001).

Carotenoids are also responsible for the colour of olive oil: the major are $\beta$-carotene and lutein in virgin olive oil (Gandul-Rojas \& Mínguez-Mosquera, 1996). The presence of these constituents depends on several factors, such as cultivar, soil and climate, and fruit maturation as well as applied conditions during olive fruit processing (Gallardo-Guerrero et al., 2002).

\section{Deterioration reaction in olive oil}

The olive oil quality is strongly related to the physiological conditions of the fruit from which it is extracted. Important chemical changes occur inside the drupe during ripening. They are related to the synthesis of organic substances, especially triglycerides, and to other enzymatic activities that may affect virgin olive oil quality. From olive oil extraction to storage operations the most common variations, recognized generally with the term "rancidity", are divided into hydrolytic and oxidative rancidity. 
The hydrolytic rancidity is a change due to the presence of water in the drupe and the catalytic action of an enzyme, the lipase, often derived by microorganisms. The reaction consists of a triglyceride hydrolysis to give glycerol and fatty acids, which result in an increase of free acidity. The release of mono-, diglycerides and finally fatty acids is obtained by the enzymatic hydrolysis.

Besides lipases, also peroxidises and lipoxygenases are numbered among the involved enzymes and they are responsible to the more or less selective formation of hydroperoxides, which will damage the native antioxidants and the polyphenoloxidases that reduce the polyphenol content, in particular on the olive paste. The enzyme activity becomes slower due to the inhibition effect of the polyphenol oxidation products. This variation regards all olive oil process, in particular the olive oil extraction systems.

The oxidative rancidity or autoxidation is due to the reaction between the oxygen and unsaturated fatty acids, free and esteryfied. It follows the characteristic trend of radicalic reactions with an induction, a propagation and a termination phase. The induction period is characterized by production of free radicals by unsaturated fatty acids or lipid peroxides (so called hydroperoxides), which constitute the primary autoxidation products. The direct attack of atmospheric oxygen on the unsaturated fatty acid chain is unfavoured from the thermodynamic point of view, because the activation energy of the reaction is high (145-270 $\mathrm{kJ} \mathrm{mol}^{-1}$ ). The direct attack could be attained by singlet oxygen which can be formed by a photochemical reaction. After the first formation, hydroperoxides are degraded to give a chain-reaction in the propagation phase: it is the principal oxidation step. Oil-quality changes related to the production of oxidized by-products that alter the sensory and nutritional characteristics of the oil include the production of carbonyl compounds, a decrease of the $\alpha$-tocopherol concentration, and the generation of off-flavour compounds. These secondary products responsible of rancid odour and flavour are represented by saturated and unsaturated aldehydes, ketones, volatile alchools, hydrocarbons, cyclic oxygenated compounds, etc. (Frankel, 2005; Morales et al., 1997). In the end of the autoxidation, reactions lead mainly to the formation of polymers (dymers oxygenated and not oxygenated according as involved reagents).

When vegetable oils are exposed to light, photo-oxidation occurs through the action of natural photosensitizers (i.e. chlorophyll), which react with triplet oxygen to form the excited state singlet oxygen. Singlet oxygen then forms free radicals from unsaturated fatty acids leading to the production of hydroperoxides and eventually to carbonyl compounds resulting to the development of undesirable off flavours in oils (Skibsted, 2000).

The reaction responsible of oxidative rancidity is so promoted by light, heat, metals traces $(\mathrm{Fe}, \mathrm{Cu}, \mathrm{Co}, \mathrm{Ni}, \mathrm{Mn})$. Substrates of these reactions are principally unsaturated free fatty acids which in general oxidize faster respect to triglycerides and phospholipids. The oxidation velocity is affected mainly by the unsaturation degree. The saturated fatty acids oxidize at a temperature higher than $60^{\circ} \mathrm{C}$, whereas the polyunsaturated fatty acids oxidize at lower temperatures. 
Other unsaturated substrates can be submitted to similar oxidation reactions, among which some hydrocarbons in the oils, in particular squalene, vitamin A, carotenoids and vitamin $\mathrm{E}$ ( $\alpha$-tocopherol). Oils and vegetable fats are more or less rich in $\alpha$-tocopherol that has a natural antioxidant activity delaying the lipid oxidation. Tocopherols are known to act as antioxidants by donating a hydrogen atom to chain-propagating peroxyl radicals (Kamal-Eldin \& Appelqvist, 1996). The oxidation of vitamins A and E and carotenoids can be also due to the peroxides action formed by unsaturated fatty acids in the secondary oxidation. This process leads to loss of vitamin activity and colour, while the essential fatty acids oxidation involves a decrease of nutritional value (Sciancalepore, 1998).

In autoxidation, virgin olive oil stability is correlated with the polar phenol content: a linear relationship between the phenolic content and oxidative stability of extra virgin olive oil has been in fact noted (Di Giovacchino et al., 1994). The main active phenols are the $o$-diphenol hydroxytyrosol and its oleosidic forms (Tsimidou, 1998, Aparicio et al., 1999) but relation between total phenol content and oil stability is not always validated. The olive oil stability to oxidation decreases in fact during the storage time, but a proportional trend to the phenols decrease is not observed. It is possible that an equilibrium attains (or tends to achieve) between polyphenols and their oxidation products, already present or formed successively to its protection versus fatty acids. This equilibrium opposes to the normal antioxidant activity of polyphenols still intact which, in these conditions, do not exert the same antioxidant activity (Lercker, 2004).

Apart from contributing to colour, carotenoids protect the oil from photo-oxidation by quenching singlet oxygen and acting as light filters (Fakourelis et al., 1987).

Chlorophyll pigments are also well-known to act as photosensitizers during light exposure. They are able to catalyze photoxidation with a velocity higher (up to 30000 times more). Chlorophylls exert an antioxidant activity dependent on the derivative present, the lipids substrate and storage temperature (Endo et al., 1985; Gutierrez-Rosales et al., 1992).

The squalene hydrocarbon has a slight antioxidant activity which is concentration dependent (Psomiadou \& Tsimidou, 1999)

\subsection{Deterioration agents in olive oil: Oxygen, light and temperature}

Among physical agents, the oxygen plays a fundamental role in the oil alteration: in contact with air it loses many qualitative characteristics as colour, flavour, odour and vitamins.

As index of oxidative deterioration, the peroxide formation in olive oil stored in closed tins is in fact generally insufficient to lead to development of the typical rancid odour, because of the limited amount of oxygen in the headspace. The lipid oxidation substrates, as previously observed, are the unsaturated molecules, while the unsaturation degree influences the oxidation velocity. The high level of natural antioxidants, associated with an excellent fatty acid composition, confers the olive oil high stability against oxidation, apart from the recognized nutritional value. 
The adoption of proper operations is also important in the preliminary phase of olive oil storage, as for example the laminar filtration by using of cartridges closed in steel cylinders that reduce the air exposition, or the filtration under nitrogen, in controlled atmosphere.

The oxygen plays an important role on the entire and complex interactions in the olive oil. Also antioxidant molecules are strongly influenced by oxygen presence. A study of changes in total polar phenols, $\alpha$-tocopherols, $\beta$-carotene, lutein, chlorophyll and squalene contents during autoxidation indicated that most interactions may be suppressed if oxygen availability is limited (Psomiadou \& Tsimidou, 2002).

Another principal harmful agent of olive oil is light, both direct and diffused and in general the UV area in the light spectrum at high energy, from 290 to $400 \mathrm{~nm}$ is the most charged. The electromagnetic radiations promote some chemical and biochemical reactions responsible of qualitative degradation as the lipid oxidation in the presence of air. In the absence of air, however, direct sunlight causes a decrease in peroxide and Kreis values of the oil. In particular, in a study on several olive oil packaging typologies, Kiritsakis (1984) revealed that the oil oxidation proceeded slowly in darkness, faster in diffused light and even faster in direct sunlight.

Moreover several natural substances have the property to absorb much the incident light and, for it, to originate alterations and/or undesirable variations. Pigments have this characteristics and colour degradation is in fact an unavoidable and well known event: many vitamins (as A and B2) are photosensitive.

The temperature controls many of reactions catalyzed by enzymes. For each increase or diminution of it a variation of biological food activity is shown. At low temperatures the kinetic energy of reagent molecules decreases, the drop of mobility and collisions necessary for the formation of enzyme-substrate complex and their products occurs. Some studies (Gambacorta et al., 2004; Kanavouras \& Coutelieris, 2006; Pristouri et al., 2010) demonstrated that high storage temperatures modify the olive oil quality, but less than the light exposition.

\section{Storage of olive oil}

According to olive variety, extra virgin olive oil has different sensorial attributes, e.g. fragrance, flavour, colour and nutrient composition parameters. Thus, its quality can be considered from diverse points of view: normative, commercial, nutritional, therapeutic and sensorial. An excellent olive oil is produced with good olive growing, harvesting, storage and processing practices. This condition considers the preservability an olive oil qualitative characteristic.

Some quality parameters of extra virgin olive oil (acidity, peroxide value and UV absorbance) can vary depending on time and storage method, reaching undesirable values at the end of the shelf life. Acidity increases with time, both in oils stored in the dark and exposed to light (Gómez-Alonso et al., 2007). Nowadays, consumers are imposing an 
increasing demand for a higher quality of extra virgin olive oil during the shelf life period. This is due to the expectation for a safe food and also for a reduction to a minimum of undesired changes in sensorial quality (Hrncirik \& Fritsche, 2005).

The olive oil storage could be shorter as possible: its assumption could not exceed the production year: the oil gains the excellence about 3-8 months after production, after that its quality starts decreasing. This behaviour depends on the olive cultivar and on the alteration of fatty fraction.

During storage the oil tends to loss the typical pigmentation and the aromatic characteristics of bitter and spicy, showing too many transparency and brilliance. Immediately after oil extraction, the flavour appears too strong and also characterized by an unpleasant aftertaste. If the olive oil is stored properly, as in well-sealed packages, it can reach the second storage year maintaining its sensory properties.

A good quality olive oil with a low acidity degree preserves its opacity for a long time. This is a characteristic of some oils, as those extracted from first harvested olives not yet completely ripe, which are very fruity and with low free acidity. The consumption of these oils, also named "new oils" is recommended up to a few weeks after bottling. For many consumers the cloudy olive oil represents a certainty of authenticity and it is also preferred in particular when the oil is purchased directly at the oil mill. It is characterized by a certain water amount (about 2-4 g/kg ) and residual solids as pectins, hemicelluloses, cellulose and mucilages in form of emulsion containing active or latent enzymatic activities as lipoxygenase, polyphenoloxidase and, principally, some esterases able to hydrolyze oleuropein, di-methyl-oleuropein and ligstroside aglycon derivatives responsible of bitter and sour flavour in virgin olive oils. The association between the natural and the healthy/nutritional aspect does not correspond to a scientific assessment because the presence of cloud induces the phenols degradation, which results in sensory changes.

Moreover fermentative processes develop on olive polysaccharides with transfer of compounds which confer sludge and warmed defects to the extracted oil. Thus, the filtration operation appears necessary, indeed is advisable before bottling and also before storage with the scope to maintain a major shelf life, avoiding settling and frequent decanting operations, which in turn induce a higher oxidation. The industrial filtration can be conducted by several systems, which differ for used material: hydrophilic cotton or cellulose at high porosity are better than fossil flour which reduces the antioxidant property because acts directly on $o$ diphenols, decreasing the amount in the olive oil and so its shelf life (Ricci, 2007).

The oil storage is favoured by the antioxidants content that prevents the rancidity, but their activity initially slows and then stops with successive formation of free radicals. This action can be enhanced by improper storage practices: for example, when storage temperature is not controlled, or when the oil is held in contact with the direct light and or at high temperatures at consumer's house, or when an improper sealing is applied after the first container opening. Concerning this last aspect, the use of screw caps is more advisable than metal pourers which expose the oil to the oxidative agents. 
As the extra virgin olive oil extraction is conducted with controlled temperatures lower than $28^{\circ} \mathrm{C}$, as the extra virgin olive oil storage requests the same attention. It has to be done with control of temperature, which may range from $10{ }^{\circ} \mathrm{C}$ to $18{ }^{\circ} \mathrm{C}$ : the correct storage temperature is $14-15{ }^{\circ} \mathrm{C}$. The high temperatures increase the chemical variation velocity and the major oil fluidity. This last effect promotes the oxygen permeation. When storage temperature decreases at $8-9{ }^{\circ} \mathrm{C}$, white deposits can appear in the oil, due to triglyceride crystallization. The higher is the content of saturated glycerides, the higher is the freeze process. The step from the oil crystallization to the solidification by lower temperatures (3-4 $\left.{ }^{\circ} \mathrm{C}\right)$ slightly increases the oil stability to the oxidation and gives substantial modifications in the sensory profile. If the clear colour maintains beside the transfer of solidified oils to warmer places, it possible that a margarinization process involved or mucilage could be present.

Finally, it is important that storing and packaging facilities respect hygiene and healthiness standards. Aromatic polycyclic hydrocarbons and benzene present in the atmosphere are absorbed by the oils contained in not hermetically sealed packages (Ricci, 2007).

\section{Packaging of olive oil}

After olive pressing, oils are transferred in tanks and after pouring they are put into storage containers where they attain their sensory characteristics. Containers are of different materials and capacity ; they are made mainly with AISI 304 inox steel which is also used for the containers intended for olive oil clarification.

The packaging in the selling container is the last unit operation: it is very important for product stability, maintaining high quality level and also value added, if carried out properly.

Reduction of oxygen in the packaging headspace and light exposure are key factors in lowering lipid oxidation and off-flavour development, thus keeping quality of olive oil.

\subsection{Olive oil packaging method}

The Regulation 1019/2002/CE (Official Journal European Union, 2002) sanctioned the prohibition of the consumer sale of the on tap olive oils. This effect promotes the consumer protection in product quality and the valorisation of farm identity. In this sense olive farms can provide packaging or ask for it to external companies. As for the other foods, the oil storage and packaging mill area must be maintained clean, ventilated, illuminated and all the unit operations should follow the hygienic-health rules according to Regulation 852/2004/CE (Official Journal European Union, 2004). As previously discussed, olive oil must be stored at constant temperature, about $14-15^{\circ} \mathrm{C}$, protected from light and air. When oils are stored in big containers (inox steel is the best material), these have to be preferably maintained quite full or better with the headspace filled with nitrogen..

For smaller quantities, the bottling with depression and the pre-bottling with inert gas are nowadays diffused by using bottlers apparatus, which saturate the headspace with nitrogen 
in bottle filling operation. In particular, bottles are hooked up by a special machine, which invert them and blow inside liquid nitrogen, which becomes gas when comes in contact with the environment, dilutes and moves out the oxygen present in the free volume of the bottle.

Then, bottle straighten up and proceeds toward the filling operation during which nitrogen stays inside because is heavier than air. As the bottle fills up and the oil level goes up, the nitrogen is carried outside avoiding anyway the oxygen penetration. The velocity of successive capping guarantees that only presence of nitrogen between cap and oil (Soressi, 2009).

Using of inert gases, as argon and nitrogen, can solve many problems and provide an optimal product storage in several production steps, as pressing, kneading and, most of all, storage and bottling. A study demonstrated in fact, that extra virgin olive oils collected from the previous harvesting season and stored under nitrogen atmosphere could be packaged in glass bottles without appreciable quality changes, as compared with seasonal extra virgin olive oil packaged in similar bottles (Guil-Guerrero \& Urda-Romacho, 2009). Nitrogen is the most used gas to protect oil from the air contact, able to remove oxygen by container headspace and pre-formed volatile contaminants. Bottling lines are very versatile for packaging typologies and easily cleanable. A past research on Italian plant typologies revealed that the prevalent packaging line is the semi-automatic $(50 \%)$, followed by the automatic $(27 \%)$ and manual $(23 \%)$ ones. The first and the third show a low specialization process level and a limited bottling capacity.

Bottle capping can be carried out by means of cork or more frequently by metal caps. A good quality cork has not to be porous and present fungal contaminants, however it is not suggested as may cause early deterioration, due to its high oxygen permeability. Metal caps are provided of a screw and a plastic soft liner that permit a perfect airtight acting as dripper. Also a thermally retractable capsule can be present on cap to seal the packaging and improve the product from the esthetical point of view. Just these last are the most used ones $(72 \%)$ respect to ones with a simple screw (15\%) and cork (11\%) (Ricci, 2007).

\subsection{Olive oil packaging materials}

In Italy and in the world the majority of consumers purchases bottled olive oil. Nowadays attention of many actors is focused on olive oil packaging, in particular on container design that often communicates the natural concept and territory link associated to the contained olive oil. Due to the changed life-style, oil container manifests also a functional property.

The nature of the packaging material has a notable influence on oil quality (Gutierrez et al., 1988). In general, a packaging is chosen depending on several criteria as product stability, environmental conditions to which food will be exposed during storage and distribution, and the product nature. In particular, the basic factors that may alter the quality of packed oils are: 
- Dissolved oxygen in the oil, that is the oxygen that remains in the container free space after it is sealed and the oxygen diffused through the walls

- $\quad$ Light, which passes through containers, activates the oxidation process

- Trace metals, in particular copper and iron

- Autocatalytic oxidation

- $\quad$ Temperature during storage

- Humidity during storage

- Dissolution of some substances from the container to the oil (Richardson, 1976).

The principal used materials for olive oil packaging are represented by glass, steel, tinplate and, in Italy to a lesser degree, plastic and polycoupled ones.

\subsubsection{Glass}

Glass represents an ancient material used in container structure: first glass containers derived by rocks date back to $3000 \mathrm{BC}$. It is formed principally by silica obtained by sand, flint or quartz. Silica is fused at very high temperatures (about $1720^{\circ} \mathrm{C}$ ) to form silicated glass. In most cases, silica is mixed with variable proportions to several raw materials: e.g. sodium and potassium carbonates (which act as stabilizer and protect the glass from the water solubilisation), lead (which confers transparency and lightness) and aluminium (which increases its hardness and lastingness). Glass is neither in a solid nor in a liquid state but glassy. Its molecules are arranged in disarray but with a sufficient cohesion to give mechanical stiffness. The structural basic unit is represented by the silica-oxygen tetrahedron, in which a silica atom is surrounded by four oxygen atoms to form a tetrahedron. Big groups tend to dispose with disorder (amorphous structure) giving the glass fragile with the tendency to rupture if submitted to an excessive tension. This induces effects on its thermal resistance that is function of container type, packaging faces and exposed surface to tension (internal if warmed and external if cooled) (Robertson, 2009).

In Italy glass is the king container for the olive oil packaging. Glass bottles can have different forms and capacities and their colour can vary largely from white to green and more dark tints. In Figure 1 several size of glass bottles are presented to demonstrate the large offer in the Italian olive oil market also of aromatized oils with spices or hot pepper.

From an Italian research about the most diffused containers, $64 \%$ of olive farms use the green glass whereas only the $10 \%$ of the total chooses the transparent one (Ricci, 2007). The best containers for the olive oil are made in opaque and dark glass: it is advisable to prefer very dark ones because little light can pass through. Since the consumer appreciates also the light glass because it is transparent and so shows the oil colour, then it is advisable to supply the bottle with a paper case which can protect the product by light. Guil-Guerriero and Urdo Romacho (2009) reported a shelf life study carried out on oils produced from Picual, Hojiblanca and Arbequina cultivars packaged in dark and transparent glass bottles. These oils showed an increase in some parameters; the variation of peroxide value was significant in extra virgin olive oils stored in transparent glass. Similar results were observed by Del Caro et al. (2006) and Vacca et al. (2006) on Bosana extra virgin olive oils. Several studies 
conducted on olive oil shelf life attested the glass as the best material for the storage (Pristouri et al., 2010), especially when oil was stored in the dark (Kanavouras et al., 2004), and for its acidity and peroxide value, with respect to other packages (Rababah et al., 2011). Finally, in a comparative study among glass, High Density Polyethylene (HDPE) and PET, results clearly indicated the glass was the best in the following ranking Glass > HDPE > PET (Ben Tekaya et al., 2007).

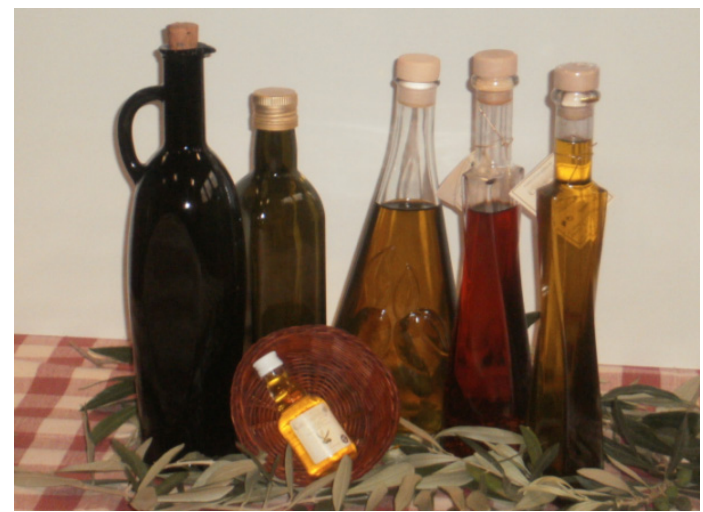

Figure 1. Several types of commercial glass bottles for olive oil.

\subsubsection{Steel and timplate}

First uses of this material date back to 1700 in domestic environment. Steel is an iron/carbon alloy: the higher the carbon percentage, the higher the rupture limit.

The tinplate is a sheet of soft steel, which is more workable because of its lower carbon content, coated on both faces by tin oxides layers and on face destined to the contact with food also by organic synthetic lacquers. Tinplate container is mainly of rectangular shape; its side seam is welded and protected with a food-approved special varnish: the welding method assures a secure side seam, avoiding the dissolution of lead into the product (Tsimis \& Karakasides, 2002).

The inox steel is an alloy containing $11 \%$ of chrome which reacts with oxygen originating an autopassivation condition due to the chrome oxides presence (Piergiovanni \& Limbo, 2010). It is the best material for the preservation of big volumes of olive oil. Compared to glass, it has the same water resistant properties (so protects the product from oxygen, humidity and microrganisms), and major advantages, e.g. handless, cleanness, shock resistance and total light protection.

A research of Grover (1982) demonstrated that the quality of oils decreases if packed in reused tinplate containers, whereas new containers did not alter oils during the one year storage period. A more recent study confirmed that the storage of oils in stainless and dark glass appears more adequate, with respect to other packaging materials, as clear PET and clear glass (Dabbou et al., 2011). 
Tin plate is used for the olive oil retail both in bigger volume size (3-5 L) and in smaller bottles (1 L). A recent study of Rababah et al. (2011) on olive oil samples stored for 60 months at light in bottles of $2.5 \mathrm{~L}$ denoted higher sedimentation amount in tinplate than in the other containers and a strong reduction of sensory attributes, probably due to the reaction of other components in olive oil, e.g. phenol compounds, with tinplate that negatively affected the descriptive attributes.

\subsubsection{Plastic materials}

Plastic materials are partially or totally synthetic organic substances. Their principal components are represented by polymers constituted by carbon, hydrogen and, in some cases, oxygen, nitrogen, chloride, silica and sulphur. They have a relatively recent history but in the time gained a large number of applications for their versatility, low production cost, low weight, their good performance and their 'thermoplastic' nature which guarantees the recyclability and consequent low environmental impact.

Plastic containers are formed by blow-moulding (extrusion blow-moulding or injection blow-moulding). One of their disadvantages is the wall permeability to gases and vapours. If transparent, they also transmit light. Migration of small molecular weight substances (e.g. monomers, oligomers and additives) from plastic to food can also occur, thus affecting the quality of food (Tsimis \& Karakasides, 2002). Oil contained in bottles with high air permeability (PE, PP, etc.) should be sold within 4 weeks, in contrast to polyvinyl chloride (PVC) bottles, which can hold olive oil for 3 months without appreciable quality loss.

PVC is a popular packaging material for edible oils in many countries, mainly due to its transparency, adaptability to all types of closure, total compatibility with existing packaging lines, and suitable for personalized design features (Kanavouras et al., 2004). PVC was used in food packaging without any doubts in 1970s. Nowadays for the dissolution of Vinyl Chloride Monomers (VCM) in oil during the storage time and for issues such as the environmental protection, the ample supply, plastic shaping, and its mechanical properties, PET has been supplanting PVC in the edible-oil market.

PET bottles are produced by bioriented extrusion and their advantages are: low water and oxygen permeability, high hardness and stiffness. PET is also more resistant to oil and fats, than the other plastic materials and for these properties it fits well for olive oil packaging. The disadvantages of this material are the processing condition (to control the humidity content), costs and the migration of acetaldehyde from bottle to food (Dipalma, 1986). As previously affirmed, plastic materials are, however, porous and thus permit the penetration of humidity and gases. Pristouri et al. (2010) demonstrated that between PET and PP, PET provided a better protection to olive oil than the other one due to its significantly lower oxygen transmission rate. Moreover Kiritsakis and Dugan (1984) reported that peroxide values were higher for olive oil packaged in plastic containers as compared to those packaged in glass bottles in the dark. Kanavouras et al. (2006) revealed instead that plastic containers had a particularly stronger protective role when oil was stored in the light, with respect to transparent glass. Besides in Italy the glass bottle is the most used, in other countries the olive oil packaging in plastic 
containers is developing. Contemporary trends in olive oil packaging include dark coloured glass bottles and PET bottles which have incorporated oxygen scavengers. These are used in order to prolong the shelf life of foods whose degradation kinetic depends on the partial pressure of oxygen inside the container. In particular, Del Nobile et al. (2003) confirmed that oxidation kinetics slower than that found with glass bottles can be obtained by bottling the olive oil into materials containing an oxygen scavenger. However, the slowest decay kinetics were obtained by bottling the oil in PET containers and by reducing the oxygen concentration prior to bottling to $10 \%$ of the equilibrium value. Also Gambacorta et al. (2004) studied the effect of several percentages of oxygen scavengers and of barrier resin included in PET on olive oil quality, and indicated that the materials having higher oxygen barrier properties can slow down the quality decay kinetics of extra virgin olive oil.

\subsubsection{Policoupled material}

Policoupled materials are mainly represented by a triple coupled material formed by Low Density Polyethylene (LDPE)/paper/LDPE and a thin aluminum foil between further polyethylene layers as barrier respectively to gas, light and liquids. It is a parallelepiped with rectangular section, the most known version of which is the Tetra Brik ${ }^{\circledR}$, also named Tetra Prisma.

Tetra Prisma allows an ideal storage for distributors and consumers. For the packaging of vegetable oils including olive oil is being used today in some Mediterranean countries, e.g. Spain and Greece, in the form of brick-type cartons and bag-in-box pouches. It is a very revolutionary packaging because guarantees a total and prolonged protection of olive oil chemical and physical characteristics up to two years. This material permits also to update the packaging aspect, with a more coloured, snappy and modern graphic design. Besides preserving the quality, Tetra Prisma allows the producer a major differentiation in packaging, logistic efficiency, lower probabilities of rupture during transfer and, not least, a $100 \%$ recyclable package. From the consumers point of view, the pack is indestructible, easy to take and handle. The realized cap contributes to protect from oxygen and it is for a prolonged use, with the aim to avoid the drip, the product spill after opening and to facilitate the pouring, regulating the flow and cutting the drip. In Italy, the olive oil packaged in Tetra Prisma was proposed in 2005 with opposite considerations (Soressi, 2007). Studies have been conducted also on this material type to evaluate its performance as container for oil. It is efficient in maintaining antioxidants in stored product for several months, due to its efficient barrier to light and oxygen, unlike the transparent glass and plastic materials, despite these last show a low gas permeability (Mendez \& Falque, 2007).

\subsection{Olive oil packaging shape and size}

Glass is the preferred packaging material in Italy for olive oil, and the most used bottle shape is the marasca type. It is chosen for three aspects: small price, the best shelf management and the functionality. The most diffused bottle volume is $0.75 \mathrm{~L}$, followed by $0.5 \mathrm{~L}$; the use of other volumes is very marginal. A research developed in 2005 on 48 
producers of biological oil in the South and the Centre of Italy indicated that the bottle largely used is that of $0,75 \mathrm{~L}$ (about $85 \%$ of the total), followed by $0,50 \mathrm{~L}$ (about $58 \%$ ) and 0,1 L (about 17\%) ones (Paffarini, 2007). Low capacity packaging is gaining market approval above all for exported products and for those directed to a medium-high consumer segment. Packaging in 0,1 L bottles is also used for very valuable oil to evidence the product value. Producers propose on market sophisticated packaging created properly to contain one or more bottles, as those for tasting of $6 \mathrm{~mL}$ volume. For the other materials (steel, tinplate and plastic) the most used volumes have been previously cited.

It is noteworthy, the recent distribution of $10 \mathrm{~mL}$ single-dose sachets, constituted by $100 \%$ extra virgin olive oil or olive oil mixed with vinegar, that is illustrated in Figure 2 with tinplate and PET containers. This type of packaging developed after the coming into effect of Italian Law 81/2006 (Official Bulletin, 2006), which bans the use of of olive oil containers without label in restaurants .

Moreover containers that can be used without common rules of hygiene and safety are also prohibited. So, it is admitted to present bottles provided of label (although their filling up is also allowed) and single-dose sachets formed by appropriate machines, which guarantee more safety and traceability of their material and because they are unable to be reused in fraudulent practice. The use of cruets is so banned because the origin of contained oil is impossible to be easily traced.

With the increase of container typologies and the research of more refined packaging in materials and graphic the supplementary cost merges into the final price that is, however, a product quality indicator (Paffarini, 2007).

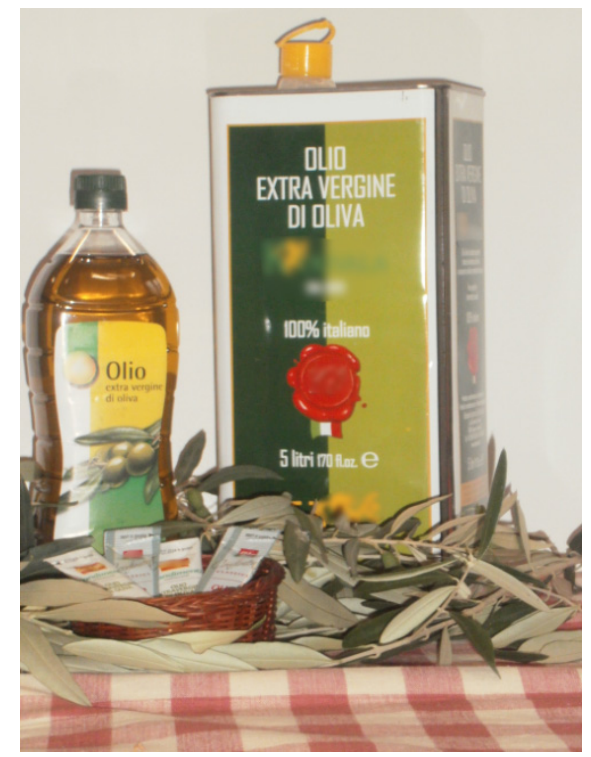

Figure 2. PET, tinplate and single-dose sachets as olive oil packaging 


\subsection{Olive oil labelling}

The olive oil labelling has two principal functions: safety for consumer and aesthetic quality. It has to follow legal requirements and so present several technical informations, some of these facultative, other obligatory. For the graphic point of view, it results as presentation of the olive oil in market shelves.

When consumer purchases olive oil, he is also more interested on symbolic contents reported in label, as the original production territory and extraction process, with respect to the sensory and chemical-physical quality of product. The oil packaging in fact satisfies curiosity about origin and characteristics by means of label, back label or attached paper, especially buying particular containers in the organized distribution. Thus, packaging elements have gained a relevant role to communicate not only product characteristics but also its history, playing on emotions that are much linked to biological oils, for example, of which label can evocate proper quality of biological agriculture.

The new Regulation 182/2009/CE (Official Journal European Union, 2009) established that labelling must obligatory indicate the extra-virgin and virgin olive oil origin. This rule does not regard a protected geographical indication (PGI) or a protected designation of origin (PDO) qualified olive oils because they are submitted to another specific normative, that is the Regulation 510/2006/CE (Official Journal European Union, 2006).

Three typologies were defined by Regulation 182/2009/CE to indicate olive oil origin:

1. Oil obtained in the same member State where olives are harvested: in this case origin can be recalled indicating State name followed by phrases as "Produced in", "Obtained in ....", and also " $100 \%$ produced in ...". The member State name can be substituted by a Communitarian reference. Then using of "produced in Italy" is allowed only if olives are produced and milled in Italy for the $100 \%$

2. Oil obtained in a member State by olives derived from other member States: in this case the origin indication can be referred as " (Extra) virgin olive oil obtained in .....by olives harvested in ...". The member State name can be substituted by a Communitarian reference If it is necessary indication of more States, they are cited in decreasing order in relation to the brought quantity

3. Mix of Communitarian and/or not Communitarian oils: in this case origin indication mode is one of the following:

a. "Mix of Communitarian olive oils", or a reference to the Community

b. "Mix of not Communitarian olive oils", or a reference to the not Communitarian origin

c. "Mix of Communitarian and not Communitarian olive oils", or a reference to Communitarian and not Communitarian origin.

Regarding the indication about sensory characteristics, the Regulation 182/2009/CE sanctions that they must be reported only in labelling of extra-virgin and virgin olive oils, besides confirm of the voluntariness. Moreover, adjectives related to a positive attribute for the oil (e.g. "intense", "medium", "light", linked to fruity, green, ripe, etc.) are admitted exclusively if derived by an objective evaluation based on the International Olive Oil 
Council method described in XII attachment of Reg. 2568/91/CE (Official Journal European Union, 1991) and revisions. The Regulation 182/2009/CE is a sort of Italian victory that can let acknowledge in a Communitarian regulation the possibility to indicate the production area of olive oils.

The question of mixing of olive oil with other vegetable oils is also well defined in the new Regulation that establishes that member States can ban in the territory the production of mix for internal consumption. Instead, they cannot prohibit on the territory the sale of mixes produced by other States and ban the mix production for the commercialization in another member State or the exportation. This regulation stopped an age-old argument in which Italian farms were penalized in particular in not Communitarian markets where did not compete at par with other member States for offer of oil mixtures. This product type is in fact requested particularly in USA and Asiatic markets.

In olive oil packaging labelling is distinguished in:

- Principal, normally rectangular, big, obligatory, that refers all terms requested by regulations

- $\quad$ Back label, not ever present, smaller and collocated generally on the back of the bottle.

It is obligatory to indicate on the label:

- Commercial and sale denomination of oil

- Oil category according to Reg. 1019/02/CE art. 3 (Official Journal European Union, 2002). For extra virgin olive oil: "Olive oil of superior category obtained directly by olives and only by mechanical extraction"

- Production or packaging plant location

- Packaging batch

- $\quad$ Product volume (e.g. 0,75 L followed by symbol)

- Preferred consume date (as consume preferably up to the end....month and year)

- Storage conditions (keep in a dry environment away from light and heat)

- Recommendation "after using not disperse into environment"

- Other facultative indications as:

- "First cold-pressing" and "cold-pressed" are reserved to virgin oils obtained by extractions not above $27^{\circ} \mathrm{C}$. To guarantee the truth of their declaration, olive farm owners could indicate the installed techniques for each stock of processed olives. The term "extracted" could be substituted by "obtained" or "produced"

- Acidity could be reported only if accompanied by peroxides value, waxes content and spectrophotometrical values ( K232, K270, Delta K ). Values can be followed by the phrase "maximum values at packaging"

- Polyphenol content only for olive oil that contains almost $5 \mathrm{mg}$ of hydroxytirosol and its derivatives per $20 \mathrm{~g}$ of olive oil. This indication must be accompanied by information to the consumer that the beneficial effect is obtained after a daily consumption of $20 \mathrm{~g}$ of olive oil. This last parameter has been fixed by a recent Regulation (Official Journal European Union, 2012) on allowed healthy information on food products. 
Anyone who reports acidity and other parameters in labelling must organize the necessary evidence to prove the conformity of product to indicated limits.

\section{Conclusions}

Olive oil storage and packaging are final steps of the production process and are as important as the other ones. Deterioration agents can decrease the quality of this important food also during these unit operations, so a correct control and monitoring of some indicators can be useful to the olive oil shelf life. Storage environment and its characteristics (temperature most of all) contribute to it.

Packaging typologies also influence the stored olive oil properties with different results depending on materials. During the time various containers were adopted and evaluated with evident feedback for qualitative aspects (some material have been in fact banned for healthy causes). Moreover, the traditional uses can give to different preferences (e.g. in Italy is very difficult to substitute the glass apart from its ascertained value as packaging material for olive oil).

Future developments are surely expected because of many attentions on this subject also by scientific community and probably some materials will be improved and other container types will be proposed in a more and more advanced food market.

\section{Author details}

Amalia Piscopo and Marco Poiana

Dipartimento di Biotecnologie per il Monitoraggio, Agroalimentare e Ambientale (Bio.M.A.A.), Mediterranean University of Reggio Calabria, Italy

\section{References}

Aparicio, R., Roda, L., Albi, M.A. \& Gutierrez, F. (1999). Effect of various compounds on virgin olive oil stability measured by Rancimat, Journal of Agricultural and Food Chemistry Vol. 47: 4150-4155.

Ben Tekaya, I., Ben Tekaya Ben Amor, I.,.Belgaied, S., El Atrache, A. \& Hassouna M. (2007) Étude du conditionnement de l'huile d'olive dans les emballages en plastique. Science des Aliments Vol. 27 (No.3): 214-233.

Cinquanta, L., Esti, M., \& La Notte, E. (1997) Evolution of phenolic compounds in virgin olive oil during storage, Journal of American Oil Chemists's Society Vol. 74: 1259.

Dabbou, S., Gharbi, I., Dabbou, S., Brahmi, F., Nakbi, A. \& Hammami, M. (2011). Impact of packaging material and storage time on olive oil quality, African Journal of Biotechnology Vol. 10 (No. 74): 16937-16947. 
Del Caro, A., Vacca, V., Poiana, M., Fenu, P., \& Piga, A. (2006). Influence of technology, storage and exposure on components of extra virgin olive oil (Bosana cv) from whole and de-stoned fruits, Food Chemistry Vol. 98 (No. 2) 311-316.

Del Nobile, M. A., Bove, S., La Notte, E., \& Sacchi, R. (2003). Influence of packaging geometry and material properties on the oxidation kinetics of bottled virgin olive oil, Journal of Food Engineering Vol. 57: 189-197.

Di Giovacchino, L., Solinas, M., \& Miccoli, M. (1994) Effect of extraction systems on the quality of virgin olive oil. Journal of American Oil Chemists's Society Vol. 71: 11891194.

Dipalma, G. (1986). Tra PET e PVC confronto all'americana, Poliplasti Vol. 383: 38-44.

Endo, Y., Usuki, R. \& Kaneda, T. (1985). Antioxidant effects of chlorophylls and pheophytin on the autoxidation of oils in the dark. II. The mechanism of antioxidative action of chlorophylls, Journal of American Oil Chemists's Society Vol. 62: 866-871.

Fakourelis, N., Lee, E.C. \& Min, D. B. (1987). Effects of Chlorophyll and $\beta$-Carotene on the Oxidation Stability of Olive Oil, Journal of Food Science Vol. 52: 234-235

Frankel, E.N. (2005). Lipid oxidation (2 ${ }^{\text {nd }}$ ed.), Bridgewater: Barnes P.J. \& Associates, The Oily Press.

Gallardo-Guerrero, L., Roca, M., \& Mínguez-Mosquera, M.I. (2002), Distribution of Chlorophylls and Carotenoids in Ripening Olives and Between Oil and Alperujo When Processed Using a Two-Phase Extraction System. Journal of American Oil Chemists's Society Vol. 79: 105-109.

Gambacorta, G., Del Nobile, M.A., Tamagnone, P., Leopardi, M., Faccia, M. \& La Notte, E. (2004). Shelf life of extra virgin olive oil stored in packages with different oxygen barrier properties, Italian Journal of Food Science vol. 16, 417-428.

Gandul-Rojas, B. \& Mínguez-Mosquera, M. I. (1996). Chlorophyll and carotenoid composition in virgin olive oils from various Spanish olive varieties, Journal of the Science of Food and Agriculture Vol. 72: 31-39.

Giuffrè, A.M., Piscopo, A., Sicari, V. \& Poiana, M. (2010). The effects of harvesting on phenolic compounds and fatty acids content in virgin olive oil (cv Roggianella), La Rivista Italiana delle Sostanze Grasse, Vol. 87 (No. 1): 14-23.

Gómez-Alonso, S., Salvador, M. D., \& Fregapane, G. (2002). Phenolic compounds profile of Cornicabra virgin olive oil, Journal of Agricultural and Food Chemistry Vol. 50: 68126817.

Gómez-Alonso, S., Mancebo-Campos, V., Salvador, M.D. \& Fregapane, G. (2007). Evolution of major and minor components and oxidation indexes of virgin olive oil during 21 months storage at room temperature, Food Chemistry Vol. 100: 36-42.

Grover, M.R. (1982). Studies on shelf-life of vegetable oils packed in tin containers, Journal of Food Science and Technology Vol. 19: 268-270.

Guil-Guerrero, J.L. \& Urda- Romacho, J. (2009). Quality of extra virgin olive oil affected by several packaging variables, Grasas y Aceites Vol. 60 (No. 2): 125-133. 
Gutierrez, F.R., Herrera, C.G., \& Gutierrez, G.Q. (1988). Estudio de la Cinética de Evolutión de los Indices de Calidad del Aceite de Oliva Virgen Durante su Conservatión en Envases Comerciales, Grasas y Aceites Vol. 39: 245-253.

Gutierrez-Rosales, F., Garrido Fernández, J., Gallardo-Guerrero, L., Gandul-Rojas, B. \& Mínguez-Mosquera, M.I. (1992). Action of chlorophylls on the stability of virgin olive oil, Journal of American Oil Chemists's Society Vol. 69: 866-871.

Hrncirik, K. \& Fritsche, S. (2005). Relation between the Endogenous Antioxidant System and the quality of Extra Virgin Olive Oil under accelerated storage conditions, Journal of Agricultural and Food Chemistry Vol. 53: 2103-2110.

IOOC - International Olive Oil Council (2007). Sensory analysis of olive oil - Method Organoleptic assessment of virgin olive oil. COI/T.20/Doc. No. 15/2nd Review. Madrid, September.

Kalua, C. M., Allen, M. S., Bedgood, D. R., Bishop, A. G., \& Prenzler, P. D. (2005). Discrimination of olive oils and fruits into cultivars and maturity stages on phenolic and volatile compounds, Journal of Agricultural and Food Chemistry Vol. 53: 8054-8062.

Kamal-Eldin, A. \& Appelqvist, L. A. (1996). The chemistry and antioxidant properties of tocopherols and tocotrienols, Lipids Vol. 31: 671-701

Kanavouras, A., Hernandez-Münoz, P., Coutelieris, F. \& Selke, S. (2004). Oxidation-Derived Flavor Compounds as Quality Indicators for Packaged Olive Oil, Journal of American Oil Chemists's Society Vol. 81, 251-257.

Kanavouras, A., \& Coutelieris, F. (2006). Shelf-life predictions for packaged olive oil based on simulations, Food Chemistry Vol. 96 (No. 1), 48-55.

Kiritsakis, A. (1998). Olive oil-Second Edition, From the tree to the table. Food and Nutrition Press, Inc. Trumbull, Connecticut, 006611, USA.

Kiritsakis, A. K., \& Dugan, L. R. (1984). Effect of selected storage conditions and packaging materials on olive oil quality, Journal of the American Oil Chemists' Society Vol. 61: 18681870.

Lairon, D. (2007). Intervention studies on Mediterranean diet and cardiovascular risk, Molecular Nutrition E Food Research Vol. 51: 1209-1214.

Lercker, G. (2004). Aspetti tecnologici e caratteristiche degli oli di oliva, Atti della "Giornata in commemorazione del Prof. Lotti", Pisa, 8 novembre 2002, 75-99.

Mendez, A. \& Falque, E. (2007). Effect of storage time and container type on the quality of extra-virgin olive oil, Food Control Vol.18 (No.5): 521-529.

Morales, M.T., Rios, J. J., \& Aparicio, R. (1997). Changes in volatile composition of virgin olive oil during oxidation: flavors and off-flavors, Journal of Agricultural and Food Chemistry Vol. 45, 2666-2673.

Official Bulletin (2006). Legge 11 marzo 2006, n. 81 "Conversione in legge, con modificazioni, del decreto-legge 10 gennaio 2006, n. 2, recante interventi urgenti per i settori dell'agricoltura, dell'agroindustria, della pesca, nonche' in materia di fiscalità d'impresa". 
Official Journal European Union (1991). Commission regulation (EEC) No 2568/91 of 11 July 1991 on the characteristics of olive oil and olive-residue oil and on the relevant methods of analysis.

Official Journal European Union (2002). Commission regulation (EC) No 1019/2002 of 13 June 2002 on marketing standards for olive oil.

Official Journal European Union (2004). Regulation (EC) No 852/2004 of 29 April 2004 of the European parliament and of the council of 29 April 2004 on the hygiene of foodstuffs.

Official Journal European Union (2006). Council regulation (EC) No 510/2006 of 20 March 2006 on the protection of geographical indications and designations of origin for agricultural products and foodstuffs.

Official Journal European Union (2009). Commission regulation (EC) No 182/2009 of 6 March 2009 amending Regulation (EC) No 1019/2002 on marketing standards for olive oil.

Official Journal European Union (2012). Commission regulation (EU) No 432/2012 of 16 May 2012 establishing a list of permitted health claims made on foods, other than those referring to the reduction of disease risk and to children's development and health.

Paffarini C. (2007) Così il packaging aiuta a catturare il consumatore, Olivo e Olio Vol. 3: 2022.

Perez-Jimenez, F., Ruano, J., Perez-Martinez, P., Lopez-Segura, F. \& Lopez-Miranda, J. (2007). The influence of olive oil on human health: not a question of fat alone, Molecular Nutrition E Food Research Vol. 51: 1199-1208.

Piergiovanni, L. \& Limbo, S. (2010). Food Packaging. Materiali, tecnologie e qualità degli alimenti, Springer.

Pregnolato, P., Maranesi, M., Mordenti, T., Turchetto, E., Barzanti, V. \& Grossi, G. (1994). Coenzimes Q10 and Q9 in some edile oils. La Rivista Italiana delle Sostanze Grasse, Vol. 71: 503-505.

Pristouri, G., Badeka, A., \& Kontominas, M. G. (2010). Effect of packaging material headspace, oxygen and light transmission, temperature and storage time on quality characteristics of extra virgin olive oil, Food Control Vol. 21: 412-418

Psomiadou, E. \& Tsimidou, M. (1998). Simultaneous HPLC determination of tocopherols, carotenoids, and chlorophylls for monitorino their effect on virgin olive oil oxidation. Journal of Agricultural and Food Chemistry Vol. 46: 5132-5138

Psomiadou E. \& Tsimidou M (1999). On the role of squalene in olive oil stability. Journal of Agricultural and Food Chemistry Vol. 47: 4025-4032.

Psomiadou, E. \& Tsimidou, M. (2001) Pigments in greek virgin olive oil: occurrence and levels Journal of the Science of Food and Agriculture Vol. 41: 640-647.

Psomiadou E. \& Tsimidou M (2002). Stability of virgin olive oil.1. Autoxidation studies, Journal of Agricultural and Food Chemistry Vol. 50: 716-721. 
Rababah, T.M., Feng, H., Yang, W., Eriefej1, K. \& Al-Omoush, M. (2011). Effects of type of packaging material on physicochemical and sensory properties of olive oil, International Journal of Agricultural and Biological Engineering Vol. 4 (No.4): 66-72.

Ranalli, A., Contento, S., Schiavone, C. \& Simone, N. (2001). Malaxing temperature affects volatile and phenol composition as well as other analytical features of virgin olive oil, European Journal of Lipid Science and Technology Vol. 103: 228-238.

Rastrelli, L., Passi, S., Ippolito, F., Vacca, G. \& De Simone, F. (2002). Rate of degradation of a-Tocopherol, squalene, phenolics and polyunsaturated fatty acids in olive oil during different storage conditions, Journal of Agricultural and Food Chemistry Vol. 50: 55665570 .

Ricci, A. (2007). Serbevolezza, i segreti di un olio che dura di più, Olivo e Olio Vol. 10: 48-52, 56-7.

Richardson, K.C. (1976). Shelf life of packaging foods. SIRO Fd Res. Q. Vol. 36 (No. 1): 17.

Robertson, G.L. (2009). Food packaging. Principles and Practice, Taylor \& Francis Group, LLC.

Sciancalepore, V. (1998) Industrie agrarie. Unione Tipografico-Editrice Torinese s.p.a. Torino

Sicari, V., Giuffrè, A.M., Piscopo, A. \& Poiana, M. (2009). Effect of the “Ottobratica” variety ripening stage on the phenolic profile of the obtained olive oil, La Rivista Italiana delle Sostanze Grasse, Vol. LXXXII (No. 4): 215-221.

Skibsted, L.H. (2000). Light induced changes in dairy product, Bulletin of the International Dairy Federation Doc. No. 345, 4-9.

Soressi M. (2007). Brik, sullo scaffale arriva un outsider, Olivo e Olio Vol. 2: 8-9.

Soressi, M. (2009). Quando l'azoto previene l'ossidazione dell'olio, Olivo e Olio Vol. 4: 30.

Tovar, M. J., Motilva, M. J. \& Romero, M. P. (2001). Changes in the phenolic composition of virgin olive oil from young trees (Olea europaea L cv. Arbequina) grown under linear irrigation strategies, Journal of Agricultural and Food Chemistry Vol. 49: 5502-5508.

Tsimidou, M. (1998). Polyphenols and quality of virgin olive oil in retrospect, Italian Journal of Food Science Vol. 10: 99-116.

Tsimis, A. \& Karakasides, N. G. (2002) How the choice of container affects olive oil quality- a review, Packaging Technology and Science Vol. 15: 147-154.

Tura, D., Gigliotti, C., Pedo, S., Failla, O., Bassi, D. \& Serraiocco, A. (2007). Influence of cultivar and site of cultivation on levels of lipophilic and hydrophilic antioxidants in virgin olive oils (Olea Europea L) and correlations with oxidative stability, Scientia Horticulturae Vol. 112: 108-119.

Vacca, V., Del Caro, A., Poiana, M. \& Piga, A. (2006) Effect of storage period and exposure conditions on the quality of Bosana extra-virgin olive oil. Journal of Food Quality Vol. 29: $139-150$ 
Vinha, A. F., Ferreres, F., Silva, B. M., Valentao, P., Gonçalves, A., Pereira, J. A., et al. (2005). Phenolic profiles of Portuguese olive fruits (Olea europaea L): Influences of cultivar and geographical origin, Food Chemistry Vol. 89: 561-568.

Viola, P. (1997). Olive Oil and Health. International Olive Oil Council, Madrid Spain, pp. 2627. 